\title{
Analisis Model Struktural Hubungan Pelatihan, Pemberdayaan, Kepuasan Kerja dan Kinerja Karyawan
}

\author{
Meilan Sugiarto $^{1^{*}}$, Marni Ningsih $^{2}$, \& Lukmono Hadi $^{3}$ \\ Administrasi Bisnis, UPN Veteran Yogyakarta, Indonesia \\ *Email: msugiarto89@gmail.com
}

\begin{abstract}
Employee performance has a crucial and decisive role in achieving an organization's success. This research conducted at PT. Madubaru Yogyakarta to investigate the impact of training that employees have participated in and empowerment on performance mediated by job satisfaction. Fifty employees of PT. Madubaru Yogyakarta used as a sample during this study. Data analysis and hypothesis testing using SEMPLS 3.2.8. This study found that training that had been attended by employees and empowerment had a significant positive effect on performance, yet as on job satisfaction. Job satisfaction alone features a significant positive impact on performance. Indirectly, job satisfaction is in a position to mediate the effect of training and individual empowerment on indirect performance, and the indirect effect is essential and decisive. PT. Madubaru Yogyakarta is suggested within the use of coaching methods to be more accurate in order to achieve the training objectives and therefore the direction of employee empowerment is more emphasized on improving performance instead of merely increasing employee satisfaction at work. Realize the targets set by the corporate within the future, the amount of employee satisfaction at work and current performance still has to be improved in order that employee contributions recover.
\end{abstract}

\begin{abstract}
Abstraksi: Kinerja karyawan memiliki peran penting dan menjadi penentu untuk mencapai kesuksesan suatu organisasi, Penelitian ini dilakukan di PT. Madubaru Yogyakarta untuk menganalisis dampak pelatihan yang pernah diikuti karyawan dan pemberdayaan terhadap kinerja yang dimediasi oleh kepuasan kerja. Limapuluh karyawan PT. Madubaru Yogyakarta dijadikan sampel dalam penelitian ini. Analisis data dan pengujian hipotesis menggunakan SEM-PLS 3.2.8. Penelitian ini menemukan bahwa pelatihan yang pernah diikuti karyawan maupun pemberdayaan berdampak signifikan yang positif terhadap kinerja, demikian pula terhadap kepuasan kerja. Kepuasan kerja sendiri, memiliki dampak signifikan yang positif terhadap kinerja. Secaara tidak langsung, kepuasan kerja mampu menjembatani pengaruh pelatihan maupun pemberdayaan secara individual terhadap kinerja secara tidak langsung, pengaruh tidak langsung tersebut bersifat signifikan dan positif. PT. Madubaru Yogyakarta disarankan dalam penggunaan metode pelatihan untuk lebih akurat agar tujuan pelatihan dapat tercapai serta arah pemberdayaan karyawan lebih ditekankan pada peningkatan kinerja bukan sekedar meningkatkan rasa puas karyawan dalam bekerja. Untuk mencapai target yang ditetapkan perusahaan di masa depan, maka tingkat kepuasan karyawan dalam bekerja maupun kinerja yang ada saat ini masih perlu ditingkatkan agar kontribusi karyawan semakin baik.
\end{abstract}

Keywords: Employee Performance; Empowerment; Job Satisfaction; Training

\section{Pendahuluan}

Sumber daya manusia merupakan unsur utama untuk kesuksesan suatu perusahaan, dengan demikian perusahaan tidak dapat hanya mengandalkan keunggulan di bidang teknologi dan kemampuan finansial saja (Sutrisno, 2009). Sumber daya manusia menjadi unsur perusahaan yang esensial karena unsur tersebut yang mengatur dan menjalankan sumber daya lain yang dimiliki perusahaan. Dengan kata lain, untuk mendukung agar perusahaan tetap eksis dan berdaya saing dalam jangka panjang dibutuhkan peran sumber daya manusia yang mampu menunjukkan kinerja yang mengarah pada pencapaian tujuan perusahaan. Kinerja yang dimaksud adalah hasil kerja, hasil pelaksanaan suatu tugas, atau hasil pelaksanaan suatu kegiatan yang ditunjukkan karyawan dalam suatu periode tertentu (Notoatmojo, 2009). Lebih lanjut, jika dikaitkan dengan kemampuan perusahaan dalam memenuhi kebutuhan dan keinginan pelanggan, adanya sumber daya manusia yang handal akan mendukung upaya tersebut dan pada akhirnya akan menciptakan keuntungan dan keunggulan bersaing bagi perusahaan. Hal tersebut dibutuhkan karena 
kelangsungan hidup perusahaan harus tetap terjaga dalam jangka panjang.

Hasil observasi dan wawancara pendahuluan dengan beberapa narasumber di PT. Madubaru Yogyakarta diperoleh infomasi bahwa tantangan perusahaan semakin berat, namun belum diimbangi oleh adanya kinerja karyawan yang maksimal. Sebagai gambaran berikut output penilaian tahunan kinerja karyawan PT. Madubaru di tahun 2014-2016:

Tabel 1. Output Penilaian Kinerja Karyawan PT. Madubaru Tahun 2014-2016

\begin{tabular}{lrrr}
\hline Ukuran Penilaian & \multicolumn{3}{c}{ Periode Penilaian } \\
\cline { 2 - 4 } Kinerja Karyawan & $\mathbf{2 0 1 4}$ & $\mathbf{2 0 1 5}$ & $\mathbf{2 0 1 6}$ \\
& $(\mathbf{\%})$ & $\mathbf{( \% )}$ & $\mathbf{( \% )}$ \\
\hline Baik Sekali & - & 0,35 & - \\
\hline Baik & 15,69 & 47,39 & - \\
\hline Cukup & 82,75 & 51,22 & 100 \\
\hline Kurang & 1,57 & 1,05 & - \\
\hline Total & 100 & 100 & 100 \\
\hline
\end{tabular}

Hal ini menjadi masalah karena kinerja karyawan belum dapat menunjukkan hasil yang maksimal, sementara harapan perusahaan adalah para karyawan mampu mengimbangi upaya perusahaan dalam menghadapi tantangan dan pencapaian tujuan jangka panjang untuk menjaga keberlanjutan perusahaan dengan menunjukkan hasil kerja yang terbaik. Namun demikian, pencapaian kinerja yang optimal dari para karyawan bukan tanpa tantangan karena berbagai faktor dapat mempengaruhinya.

Karyawan akan menjadi semakin produktif, kreatif, fleksibel, inovatif, serta loyal ketika merasakan adanya kepuasan dalam dirinya dan cenderung menunjukkan sikap positif dalam menyelesaikan pekerjaan (Mohammed and Eleswed, 2013). Dengan kata lain, kinerja karyawan ditentukan oleh sejauhmana kepuasan kerja yang dirasakan oleh para karyawan (Karatepe, 2012; Sari dan Susilo, 2018). Jadi kepuasan karyawan dalam bekerja dapat menjadi salah satu variabel kunci kesuksesan organisasi, dan hal tersebut membutuhkan perhatian khusus dalam rangka menghilangkan dampak negatif terhadap kinerja organisasi (Bakotic' and Babic', 2013). Luthans (2005) menegaskan bahwa kepuasan kerja merupakan topik yang diteliti secara luas yang menarik perhatian dari banyak peneliti yang berasal dari berbagai disiplin. Kepuasan kerja dapat dievaluasi berdasarkan karakteristik pekerjaan dan perasaan karyawan tentang pekerjaannya.

Peningkatan kinerja karyawan sebagaimana yang diharapkan oleh banyak perusahaan biasanya dilakukan melalui pelatihan karena pelatihan merupakan salah satu cara dalam mengatasi gap kompetensi karyawan, dimana setiap perusahaan biasanya menetapkan kemampuan dan keterampilan tertentu untuk suatu jabatan agar karyawan pada jabatan tersebut mampu melaksanakan tugas-tugas yang tercantum dalam deskripsi pekerjaannya, namun dalam kenyataannya tidak semua karyawan secara langsung mampu memenuhi persyaratan tersebut. Untuk itu pelatihan dapat digunakan untuk membantu karyawan meminimalkan gap terutama ketika penurunan kinerja karyawan terjadi (Ataunur dan Ariyanto, 2015). Selain itu, pelatihan yang diikuti karyawan dapat menjadi media dalam rangka membangkitkan semangat kerja karyawan, menghilangkan gap, meminimalisir pengaruh tidak baik akibat minimnya pendidikan, kurangnya pengalaman kerja, kepercayaan diri yang rendah dari individu atau timkerja (Utomo dan Sugiarto, 2007). Secara empiris, penelitian terdahulu menemukan bukti pelatihan memiliki dampak pada kepuasan kerja (Rizwan et al.,2012; Khuong and Tien, 2013; Sihombing dkk., 2016) serta berdampak pada kinerja karyawan (Nkosi, 2015; Kartikasari, R. dan Djastuti, 2017).

Untuk dapat mendorong karyawan dalam bekerja, pemberdayaan merupakan langkah strategis yang perlu dilakukan oleh setiap perusahaan. Pemberdayaan akan memberikan karyawan kesempatan untuk memainkan peranan yang lebih besar di perusahaan, seperti berkontribusi dalam penentuan suatu keputusan atau memperoleh lebih banyak kewenangan dalam bekerja (Madura, 2007). Memberi karyawan tanggungjawab yang besar adalah suatu kepercayaan, keberanian memberikan tanggung jawab yang besar merupakan suatu cara untuk mempertahankan dan meningkatkan kemampuan karyawan (Irmim, 2005). Eksistensi karyawan yang dirasakan dengan adanya pemberdayaan dapat 
meningkatkan komitmen organisasional dan kepuasan kerja (Ongori, 2009). Hasil penelitian Pratama dan Sriathi (2015) menunjukkan bukti bahwa pemberdayaan berdampak pada kepuasan kerja. Lebih lanjut, pemberdayaan karyawan dalam organisasi terbukti secara empiris berdampak signifikan terhadap kinerja karyawan (Nielsen \& Pedersen, 2003; Ayuningtyas dan Djastuti, 2017).

\section{Kajian Teori dan Hipotesis Penelitian}

\section{Kinerja Karyawan}

Kinerja karyawan dapat diartikan sebagai jenjang keberhasilan seseorang dalam menyelesaikan pekerjaan selama waktu tertentu (Veitzal dan Basri, 2005). Keberhasilan yang dimaksud mencakup kualitas serta kuantitas (Mangkunegara, 2009). Pengertian lain mengartikan kinerja karyawan sebagai output yang mampu diraih individu dari penyelesaian terhadap beban kerja dengan mendasarkan pada kemampuan, pengalaman, keseriusan, dan kesempatan yang dimiliki (Hasibuan, 2014). Dengan demikian, kinerja karyawan adalah hasil dari sebuah proses (Suryadi, 2010).

Kinerja karyawan merupakan salah satu luaran organisasional, Rae (2013) menegaskan bahwa kepuasan kerja merupakan faktor kritis yang dapat mempengaruhi berbagai luaran utama organisasional. Dengan kata lain, kinerja sebagai salah satu luaran organisasional akan dipengaruhi oleh kepuasan kerja karyawan. Lebih lanjut, Vasudevan (2014) menjelaskan pelatihan sangat dibutuhkan untuk semua karyawan dalam rangka untuk memastikan bahwa mereka dapat bekerja dengan baik untuk tugas yang diberikan. Pelatihan melimpahkan karyawan dengan keterampilan dan memperkuat kemampuan dalam kinerja (Palo and Padhi, 2003). Karyawan yang diberdayakan dalam berbagai organisasi biasanya akan menjaga kompetensinya untuk melaksanakan tugas sebagaimana diharapkan dengan menerapkan pengetahuan dan keterampilannya (Jacquiline, 2014). Dengan demikian, pemberdayaan akan berdampak signifikan terhadap kinerja karyawan (Ayuningtyas dan Djastuti, 2017; Irmim, 2005).

\section{Kepuasan Kerja Karyawan}

Kepuasan kerja karyawan diartikan sebagai harapan, kebutuhan maupun nilai pekerjaan yang dirasakan karyawan dibandingkan dengan kenyataan yang diterima tentang pekerjaan tersebut (Heslop et al., 2002; Luthans, 2005). Pengertian lain tentang kepuasan kerja karyawan merupakan tingkat yang berkaitan dengan sikap suka atau tidak suka dari karyawan terhadap pekerjaannya (Saif and Saleh, 2013). Kepuasan kerja juga dapat diartikan sebagai akhir dari penyelesaian pekerjaan atau tugas oleh individu. Dengan demikian, kepuasan kerja merupakan kemampuan pekerjaan yang dilakukan tersebut untuk memenuhi kebutuhan dan harapan karyawan. Penilaiannya dapat positif atau negatif tergantung pada apakah kebutuhan terpuaskan atau tidak (Gupta, 2012). Armstrong (2006) mensyaratkan kepuasan kerja sebagai perpaduan pemikiran karyawan terhadap aktivitas mereka.

\section{Pelatihan}

Secara konseptual, pelatihan diartikan sebagai sebuah proses pembelajaran yang dibutuhkan oleh karyawan berkaitan dengan ketrampilan fundamental untuk melaksanakan pekerjaannya (Dessler, 2010). Ditegaskan pula bahwa pelatihan adalah suatu upaya perbaikan terhadap keterampilan dan metode untuk melakukan suatu pekerjaan secara teliti dan kontinyu, baik saat ini atau dimasa datang (Utomo dan Sugiarto, 2007). Pelatihan dapat pula didefinisikan sebagai penambahan keterampilan dalam rangka meraih sasaran yang sudah ditentukan secara terukur, dimana hal tersebut seharusnya mengarah pada perubahan perilaku yang diinginkan (Wagonhurst, 2002). Lebih lanjut, pelatihan merupakan sebuah proses sistematik dengan tujuan mengajari karyawan cara untuk lebih produktif di tempat kerjanya melalui perbaikan pengetahuan, keterampilan, atau perilaku secara terprogram dengan baik (Buckley and Caple, 2000).

\section{Pemberdayaan}

Thomas and Velthouse (1990) mendefinisikan pemberdayaan sebagai tingkat tertinggi dari kemauan menyelesaikan tugas yang berasal dari dalam diri individu. 
Sementara Bandura (1986) menyatakan pemberdayaan sebagai sebuah harapan efikasi diri. Pemberdayaan dirasakan karyawan ketika mereka merasakan dan memperoleh kekuasaan untuk berhadapan dengan situasi, kejadian, atau individu dengan menggunakan keterampilan dan pengetahuan mereka (Conger and Kanungo, 1988). Selain itu, pemberdayaan dapat dijadikan sebuah strategi yang efektif bagi organisasi yang ingin meningkatkan kapabilitas dan tanggungjawab karyawannya, karena pada prinsipnya jika karyawan diberdayakan, maka akan lebih efisien dalam mengerjakan tugasnya (Saifullah et al., 2015).

Keterkaitan antara Pelatihan, Pemberdayaan, Kepuasan Kerja Karyawan dan Kinerja Karyawan

Pelatihan dinilai merupakan faktor penting bagi perilaku individu. Beberapa penelitian terdahulu menemukan adanya efek positif dari pelatihan pada kepuasan kerja karyawan (Adesole, Oyeniyi, and Adeyemi, 2013; Khuong and Tien, 2013; Rizwan et al.,2012; Chiang, Back, and Canter, 2005). Hasil penelitian Nkosi (2015) menunjukkan pelatihan berdampak nyata dan mampu meningkatkan organisasional komitmen, retensi, dan kinerja karyawan, dimana dampak pelatihan terbesar adalah terhadap kinerja karyawan. Berbagai penelitian sebelumnya secara empiris telah memberikan bukti adanya dampak pemberdayaan karyawan secara positif pada kepuasan kerja karyawan (Wadhwa and Verghese, 2015; Chang, Shih, and Lin, 2010; Davies, Laschinger, and Andrusyszyn, 2006). Pemberdayaan karyawan juga menekankan bahwa keberadaan karyawan dalam organisasi bernilai tinggi sehingga dapat meningkatkan komitmen organisasional dan kepuasan kerja karyawan (Ongori, 2009). Bukti empiris lain membuktikan adanya hubungan positif antara pemberdayaan karyawan dengan produktivitas dan kinerja (Nielsen \& Pedersen, 2003). Meningkatnya kinerja karyawan terbukti disebabkan oleh meningkatnya kepuasan kerja karyawan (Sari dan Susilo, 2018; Karatepe, 2012; SousaPoza, 2000). Karyawan yang puas akan lebih meningkatkan kinerja organisasi (Khan et al., 2011).
Berdasarkan penjelasan tentang keterkaitan antara variabel penelitian, berikut ini hipotesis yang diformulasikan dan selanjutnya diuji melalui penelitian ini:

H1. Pelatihan berpengaruh positif terhadap kepuasan kerja karyawan.

H2. Pelatihan berpengaruh positif terhadap kinerja karyawan.

H3. Pemberdayaan berpengaruh positif terhadap kepuasan kerja karyawan.

H4. Pemberdayaan berpengaruh positif terhadap kinerja karyawan.

H5. Kepuasan kerja karyawan berdampak positif terhadap kinerja karyawan.

H6. Pengaruh pelatihan terhadap kepuasan kerja karyawan akan berdampak pada kinerja karyawan.

H7. Pengaruh pemberdayaan terhadap kepuasan kerja akan berdampak pada kinerja karyawan.

\section{Metode}

Penelitian yang telah dilakukan merupakan explanatory research, dengan tujuan untuk menguji pengaruh pelatihan, pemberdayaan, kepuasan kerja karyawan, dan kinerja karyawan melalui pengujian hipotesis yang telah dirumuskan sebelumnya.

Sampel penelitian ini diambil dengan pendekatan simple random sampling dengan ukuran sampel sejumlah 50 orang yang merupakan karyawan tetap PT. Madubaru Yogyakarta. Jumlah tersebut dianggap layak untuk sebuah penelitian multivariat karena untuk penelitian multivariat batasan jumlah sampel yang layak adalah 30 sampai dengan 50 obyek penelitian (Roscoe dalam Sugiyono, 2014).

Selanjutnya, kuesioner digunakan dalam penelitian ini sebagai instrumen pengumpulan data, dimana para responden diminta mengisi langsung kuesioner tersebut. Tingkat respon yang diperoleh adalah $100 \%$, dimana dari 50 kuesioner yang dibagikan semua terisi lengkap oleh para responden. Pelaksanaan pengumpulan data penelitian dilakukan pada bulan Januari - Pebruari 2019. Kuesioner yang dibagikan pada para responden secara substansial dibagi menjadi dua bagian, pada bagian pertama berisi pertanyaan yang berkaitan dengan data tentang karakteristik responden seperti jenis 
kelamin, umur, tingkat pendidikan akhir. Sedangkan, pada bagian kedua dari kuesioner berisi item pertanyaan yang digunakan untuk mengukur variabel penelitian. Pelatihan diukur dengan 8 item yang merupakan pengembangan dari dimensi pelatihan dari Bangun (2012). Selanjutnya, pemberdayaan diukur dengan 8 item yang dikembangkan berdasarkan dimensi pemberdayaan dari Spreitzer (1995) dan Zhung and Bartol (2010). Pengukuran kepuasan kerja dengan 9 item yang dikembangkan dari dimensi kepuasan kerja dari Spector (1997) dan Luthans (2005). Kinerja karyawan diukur dengan 6 item yang dikembangkan dari dimensi kinerja dari Mathis and Jackson (2000). Skala Likert 5 poin mulai dari 1 (sangat tidak setuju) sampai 5 (sangat setuju) digunakan untuk mengukur pilihan jawaban responden untuk setiap item.

Analisis data dan pengujian hipotesis menggunakan program SEM-PLS 3.2.8. Dasar penerimaan dan penolakan hipotesis adalah hasil perbandingan nilai t-statistic dengan t-table. Melalui penggunaan SEMPLS tersebut uji validitas dan realibilitas juga sekaligus dilakukan.

\section{Hasil}

Output Uji Validitas Item dan Konsistensi Instrumen Penelitian

Pengujian tingkat validitas item melalui SEM-PLS menggunakan convergent validity yang mendasarkan nilai loading factor hasil reestimasi setiap item, dimana item dikatakan valid jika nilai loading factor $>0,70$ (Ghozali

Tabel 2. Output outer loading

\begin{tabular}{|c|c|c|c|c|}
\hline Item & Pelatihan & Pemberdayaan & Kepuasan Kerja & Kinerja Karyawan \\
\hline P1 & 0,650 & & & \\
\hline $\mathrm{P} 2$ & 0,681 & & & \\
\hline P3 & 0,762 & & & \\
\hline $\mathrm{P} 4$ & 0,825 & & & \\
\hline P5 & 0,766 & & & \\
\hline P6 & 0,755 & & & \\
\hline P7 & 0,563 & & & \\
\hline $\mathrm{P} 8$ & 0,655 & & & \\
\hline PK1 & & 0,685 & & \\
\hline PK2 & & 0,642 & & \\
\hline PK3 & & 0,776 & & \\
\hline PK4 & & 0,791 & & \\
\hline PK5 & & 0,780 & & \\
\hline PK6 & & 0,709 & & \\
\hline PK7 & & 0,617 & & \\
\hline PK8 & & 0,636 & & \\
\hline KPS1 & & & 0,707 & \\
\hline KPS2 & & & 0,700 & \\
\hline KPS3 & & & 0,619 & \\
\hline KPS4 & & & 0,597 & \\
\hline KPS5 & & & 0,828 & \\
\hline KPS6 & & & 0,790 & \\
\hline KPS7 & & & 0,714 & \\
\hline KPS8 & & & 0,631 & \\
\hline KPS9 & & & 0,750 & \\
\hline KN1 & & & & 0,622 \\
\hline KN2 & & & & 0,783 \\
\hline KN3 & & & & 0,841 \\
\hline KN4 & & & & 0,851 \\
\hline KN5 & & & & 0,833 \\
\hline KN6 & & & & 0,613 \\
\hline
\end{tabular}


dan Latan, 2015). Hasil uji PLS Algorithm tahap awal yang disajikan dalam Tabel 1 menunjukkan item P3, P4, P5, dan P6 dari konstruk pelatihan memiliki nilai loading factor 0,$762 ; 0,825 ; 0,766 ; 0,755$, dimana nilai tersebut $>0,70$ maka item-item tersebut dinyatakan valid. Selanjutnya item yang valid untuk konstruk pemberdayaan adalah PK3, PK4, PK5, dan PK6 dengan nilai loading factor 0,$776 ; 0,791 ; 0,780 ; 0,709$. Sementara item yang valid untuk konstruk kepuasan kerja karyawan yaitu KPS1, KPS2, KPS5, KPS6, KPS7, dan KPS9 dengan nilai loading factor 0,$707 ; 0,700 ; 0,828 ; 0,790 ; 0,714$; 0,750 . Item yang valid untuk konstruk kinerja karyawan mencakup $\mathrm{KN} 2, \mathrm{KN} 3, \mathrm{KN} 4$, dan KN5 dengan nilai loading factor 0,783; 0,$841 ; 0,851 ; 0,833$. Setelah mendapatkan item-item yang valid untuk setiap konstruk, selanjutnya dilakukan uji bootstrapping SEM-PLS.

Tabel 3. Output Cronbach's Alpha, Composite Reliability dan Average Variance Extraced (AVE)

\begin{tabular}{lcrr}
\hline Konstruk & $\begin{array}{c}\text { Cronbach's } \\
\text { Alpha }\end{array}$ & $\begin{array}{c}\text { Composite } \\
\text { Reliability }\end{array}$ & AVE \\
\hline Pelatihan & 0,803 & 0,871 & 0,628 \\
Pemberdayaan & 0,763 & 0,849 & 0,585 \\
Kepuasan & 0,863 & 0,896 & 0,589 \\
Kerja & & & \\
Kinerja & 0,844 & 0,896 & 0,684 \\
Karyawan & & & \\
\hline
\end{tabular}

Nilai Cronbach's Alpha lebih dari 0,70 dan Composite Reliability (Average Variance Extraced lebih dari 0,05 merupakan persyaratan untuk menentukan konsisten atau reliabilitas instrumen penelitian dalam uji SEM-PLS (Ghozali dan Latan, 2015). Tabel 3 menunjukkan nilai Cronbach's Alpha untuk setiap konstruk penelitian antara 0,763 sampai dengan 0,863 dan nilai Composite Reliability yang diperoleh adalah 0,849 sampai dengan 0,896 serta Average Variance Extraced (AVE) antara 0,585 sampai dengan 0,684 . Dengan demikian persyaratan reliabilitas dipenuhi oleh setiap konstruk.

\section{Pengujian Hipotesis}

Pengujian hipotesis didasarkan output bootstrapping SEM-PLS, sehingga dapat diperoleh koefisien jalur (path coefficients) pengaruh variabel bebas terhadap variabel terikat, baik secara langsung maupun melalui variabel intervening dalam model. Berdasarkan data pada Tabel 3 pelatihan memiliki efek yang signifikan dan berdampak positif pada kepuasan kerja karyawan (path coefficient $=0,250 ;$ - -statistic $=2,269>$ t-table $=1,96 ; \mathrm{P}$ Value $<0,024)$, demikian pula terhadap kinerja karyawan ( path coefficient $=0,307 ;$ t-statistic $=2,630>$ t-table $=1,96 ; \mathrm{P}$ Value $<0,009)$. Hasil penelitian tersebut mendukung $\mathrm{H} 1$ dan $\mathrm{H} 2$, sehingga kedua hipotesis dapat diterima. Di sisi lain, pemberdayaan yang dirasakan oleh karyawan memiliki efek yang signifikan dan berdampak positif terhadap kepuasan kerja karyawan (path coefficient $=0,645 ;$ - -statistic $=7,027>$ t-table $=1,96 ; \mathrm{P}$ Value $<0,000$ ), maka hasil penelitian ini mendukung dan menerima H3. Pemberdayaan juga memiliki efek yang signifikan dan berdampak positif terhadap kinerja karyawan (path coefficient $=$ 0,$309 ;$ t-statistic $=2,054>$ t-table $=1,96 ; \mathrm{P}$ Value $<0,041)$, hasil pengujian tersebut mendukung dan menerima H4. Hasil pengujian pengaruh kepuasan kerja karyawan terhadap kinerja karyawan menunjukkan hasil adanya pengaruh kepuasan kerja yang signifikan dan berdampak positif pada kinerja karyawan (path coefficient $=0,377$; $t$-statistic

Tabel 4. Path coefficients

\begin{tabular}{lcccccc}
\hline & $\begin{array}{c}\text { Path } \\
\text { Coefficients }\end{array}$ & $\begin{array}{c}\text { Sample } \\
\text { Mean }\end{array}$ & SD & t statistic & p values & Keterangan \\
\hline $\mathrm{P} \rightarrow \mathrm{KPS}$ & 0,250 & 0,262 & 0,110 & 2,269 & 0,024 & Sig. + \\
\hline $\mathrm{P} \rightarrow \mathrm{KN}$ & 0,307 & 0,304 & 0,117 & 2,630 & 0,009 & Sig. + \\
\hline $\mathrm{PK} \rightarrow \mathrm{KPS}$ & 0,645 & 0,049 & 0,092 & 7,027 & 0,000 & Sig. + \\
\hline $\mathrm{PK} \rightarrow \mathrm{KN}$ & 0,309 & 0,308 & 0,150 & 2,054 & 0,041 & Sig. + \\
\hline $\mathrm{KPS} \rightarrow \mathrm{KN}$ & 0,377 & 0,373 & 0,154 & 2,447 & 0,015 & Sig. + \\
\hline $\mathrm{P} \rightarrow \mathrm{KPS} \rightarrow \mathrm{KN}$ & 0,104 & 0,208 & 0,101 & 1,997 & 0,046 & Sig. + \\
\hline $\mathrm{PK} \rightarrow \mathrm{KPS} \rightarrow \mathrm{KN}$ & 0,243 & 0,241 & 0,105 & 2,321 & 0,021 & Sig. + \\
\hline
\end{tabular}




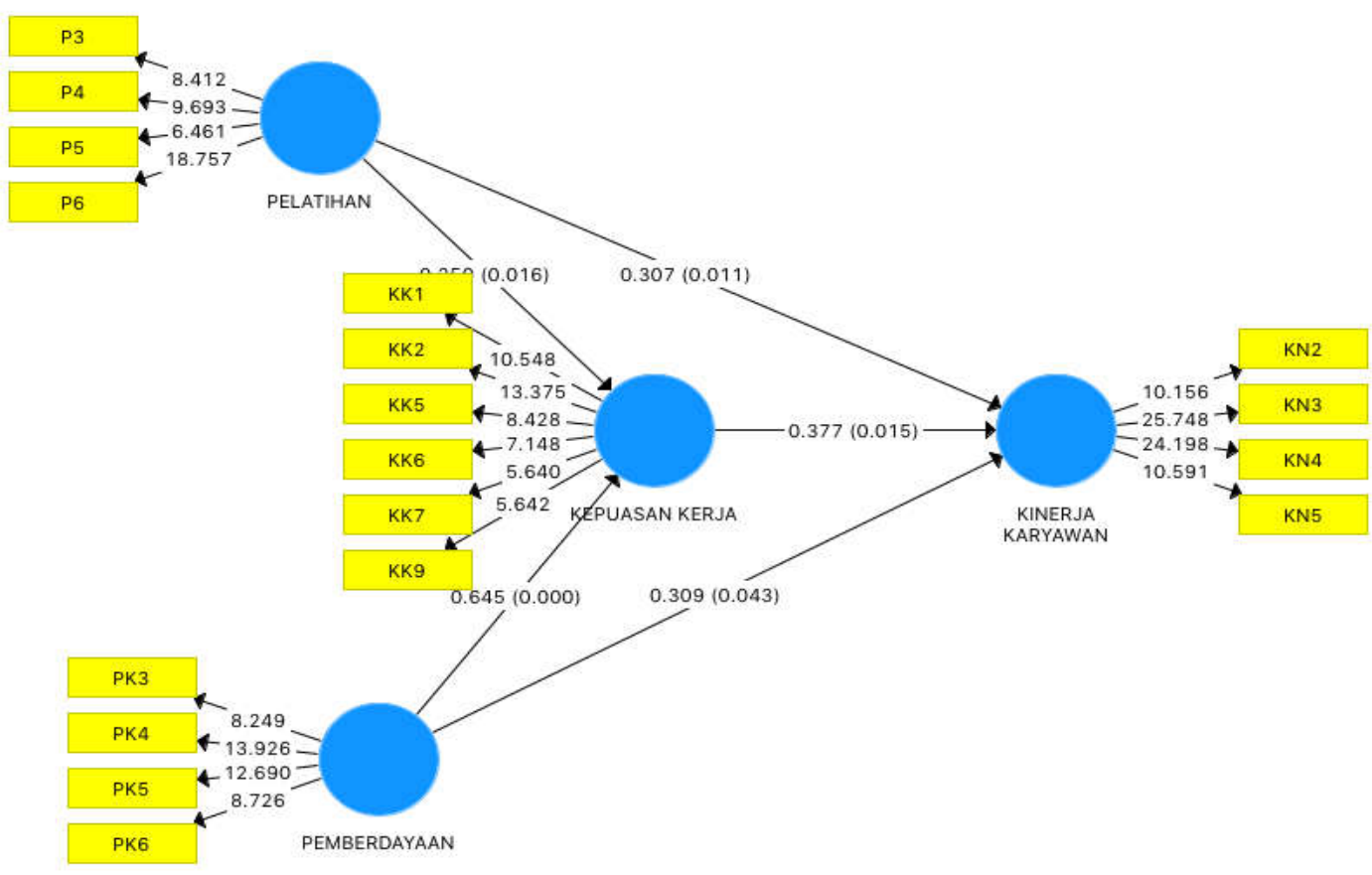

\section{Gambar 1. Output bootstrapping SEM-PLS}

$=2,447>$ t-table $=1,96 ; \mathrm{P}$ Value $<0,015)$

Peran kepuasan kerja sebagai variabel mediator yang digambarkan dalam model, dimana variabel tersebut memediasi dampak tidak langsung pelatihan terhadap kinerja karyawan terbukti signifikan dan dampak tidak langsung yang ditimbulkan bersifat positif ( path coefficient $=0,104$; $t$-statistic $=$ $1,997>$ t-table $=1,96 ; \mathrm{P}$ Value $<0,046$ ). Dengan demikian, hasil tersebut mendukung dan menerima pernyataan sebagaimana yang dirumuskan dalam H6. Kepuasan kerja juga memediasi dampak tidak langsung pemberdayaan pada kinerja karyawan dan dampak tidak langsung tersebut signifikan ( path coefficient $=0,243 ;$ t-statistic $=2,321>$ $t$-table $=1,96 ; \mathrm{P}$ Value $<0,021)$, maka H7 dapat diterima.

\section{Pembahasan}

Pengaruh parsial setiap konstruk dalam model, seperti adanya dampak yang signifikan pelatihan terhadap kepuasan kerja maupun terhadap kinerja karyawan dan dampak pelatihan tersebut bersifat positif, baik terhadap kepuasan kerja maupun terhadap kinerja karyawan. Hasil tersebut sejalan dengan berbagai penelitian sebelumnya antara lain: Nkosi (2015); Khuong and Tien, (2013); Adesole, Oyeniyi, and Adeyemi (2013); Rizwan et al. (2012). Dampak langsung pelatihan dalam penelitian ini lebih kuat terhadap kinerja karyawan dibandingkan dampak terhadap kepuasan kerja $(\beta=0,307>\beta=0,250)$. Hal ini dapat disebabkan karena pada dasarnya penekanan utama sebagian besar perusahaan memberikan pelatihan pada karyawannya dengan tujuan utama untuk meningkatkan kinerja. Secara konseptual, pelatihan sangat dibutuhkan untuk memastikan bahwa karyawan dapat bekerja dengan baik untuk tugas yang diberikan (Vasudevan, 2014), dimana karyawan mendapat keterampilan lebih dan memperkuat kemampuan dalam kinerja (Palo and Padhi, 2003). Hasil analisis deskriptif mendukung adanya temuan tersebut, dimana rerata item yang diperoleh 
untuk variabel pelatihan menunjukkan skor rerata tertinggi bahwa pelatihan sangat membantu karyawan dalam menyelesaikan pekerjaan $(4,24)$, kemudian diikuti dengan pemberian materi pelatihan sesuai yang dibutuhkan karyawan (4,16), setelah mengikuti pelatihan menimbulkan kepercayaan diri karyawan dalam bekerja $(4,14)$, pelatihan meningkatkan keterampilan karyawan $(4,12)$, pelatihan mampu mengurangi tingkat kesalahan karyawan dalam bekerja $(4,10)$, materi yang diberikan dapat dipahami karyawan $(4,06)$, hasil pelatihan banyak terpakai dalam pekerjaan karyawan $(4,04)$, dan ada kesesuaian antara metode dan tujuan pelatihan $(3,92)$.

Selanjutnya, hasil penelitian ini menunjukkan pemberdayaan secara parsial memiliki dampak signifikan terhadap kepuasan kerja maupun terhadap kinerja karyawan dan dampak tersebut bersifat positif. Hasil tersebut sejalan dengan penelitian yang pernah dilakukan oleh Wadhwa and Verghese (2015) dan Chang, Shih, and Lin (2010). Pengaruh pemberdayaan dalam penelitian ini lebih kuat terhadap kepuasan kerja dibandingkan terhadap kinerja $(\beta=0,645>0,390)$. Hal ini dapat disebabkan pemberdayaan yang dirasakan karyawan dinilai dalam rangka meningkatkan self of belonging diantara mereka dan merasa dihargai (Ongori, 2009). Hasil tersebut berbeda dengan penelitian sebelumnya yang berpendapat bahwa karyawan yang diberdayakan akan menjaga kompetensinya menyelesaikan beban kerja sebagaimana diharapkan (Jacquiline, 2014). Kondisi tersebut sesuai dengan analisis deskriptif dari pemberdayaan karyawan, dimana skor rerata tertinggi bahwa dengan adanya pemberdayaan karyawan yakin akan kemampuannya dalam melakukan pekerjaan yang ditugaskan kepadanya $(4,10)$, kemudian diikuti dengan karyawan percaya kompetensi yang dimiliki mampu mencapai target pekerjaannya $(4,04)$, karyawan dapat menggunakan banyak cara untuk mencapai tanggung jawab pekerjaannya $(4,04)$, karyawan merasa pekerjaannya berdampak besar terhadap pekerjaan orang lain $(4,04)$, karyawan merasa jabatan yang dimiliki sekarang sesuai kemampuannya $(3,94)$, karyawan merasa tugad dan tanggungjawab yang dibebankan padanya sesuai dengan kemampuannya $(3,90)$, karyawan memiliki kesempatan untuk tidak tergantung pada atasan dan bebas dalam melakukan pekerjaan $(3,88)$, dan karyawan merasa apa yang dilakukannya berpengaruh besar pada departemen tempat kerjanya $(3,86)$.

Kepuasan kerja secara parsial berdampak signifikan terhadap kinerja karyawan dan dampak kepuasan kerja tersebut bersifat positif. Penelitian sebelumnya (Sari dan Susilo, 2018; Karatepe, 2012; Sousa-Poza, 2000) sejalan dengan hasil penelitian tersebut. Hasil analisis deskriptif menunjukkan skor rerata tertinggi untuk item yang berkaitan dengan kepuasan kerja karyawan adalah saling mendukungnya sesama pekerja dalam menyelesaikan pekerjaan $(4,16)$, kemudian diikuti dengan karyawan menyukai pekerjaan mereka saat ini $(4,12)$, kepuasan karyawan terhadap rekan kerja karena mudah dalam bekerjasama $(4,06)$, kepuasan karyawan terhadap pekerjaan yang mereka kerjakan saat ini $(4,04)$, kepuasan karyawan dengan cara atasan menangani para pekerja yang patut diteladani $(3,88)$, kepuasan karyawan terhadap perusahaan memberikan kesempatan untuk naik jabatan $(3,82)$, puas dengan gaji yang terima karena diatas UMR $(3,76)$, puas dengan prestasi karena dapat memiliki peluang naik golongan $(3,76)$, gaji yang diterima sesuai dengan tuntutan pekerjaan yang dibebankan $(3,72)$.

Penelitian ini menemukan adanya peran kepuasan kerja karyawan sebagai variabel mediator yang signifikan dalam memediasi dampak tidak langsung pelatihan terhadap kinerja karyawan. Adanya peran yang signifikan kepuasan kerja tersebut dapat dijelaskan secara statistik karena pengaruh pelatihan pada kepuasan kerja adalah signifikan $(t$-statistic $=2,269>t$-table $=$ 1,96) selanjutnya pengaruh kepuasan kerja terhadap kinerja karyawan juga signifikan $(t-$ statistic $=2,447>$ t-table $=1,96)$. Peran mediator kepuasan kerja berlaku pula pada dampak tidak langsung pemberdayaan terhadap kinerja karyawan, dimana pengaruh pemberdayaan terhadap kepuasan kerja adalah signifikan ( $t$-statistic $=7,027>t$-table $=1,96)$, kemudian pengaruh kepuasan kerja terhadap kinerja karyawan juga signifikan. Namun demikian, ditinjau dari kuat lemahnya pengaruh antar konstruk, dimana 
dampak langsung pelatihan terhadap kinerja karyawan memiliki nilai path coefficient $=$ 0,307 , sedangkan pengaruh tidak langsung pelatihan melalui kepuasan kerja terhadap kinerja karyawan dengan nilai path coefficient $=0,104$. Dengan demikian, pengaruh langsung pelatihan lebih kuat dibandingkan pengaruh tidak langsungnya. Di sisi lain, terjadi hal yang sama dengan pemberdayaan, dimana pengaruh langsung pemberdayaan terhadap kinerja karyawan memperoleh nilai path coefficient $=0,309$, sedangkan nilai path coefficient untuk pengaruh tidak langsung pemberdayaan terhadap kinerja karyawan melalui kepuasan kerja adalah 0,243.

\section{Kesimpulan dan Saran}

Mengacu pada temuan dari penelitian ini, maka dapat ditarik kesimpulan: a) pelatihan berpengaruh positif terhadap kepuasan kerja karyawan atau dengan kata lain meningkatnya kepuasan kerja karyawan dapat disebabkan karena pelatihan yang diikuti karyawan sesuai dengan kebutuhannya; b) pelatihan berpengaruh positif terhadap kinerja karyawan atau dengan kata lain meningkatnya kinerja karyawan dapat disebabkan oleh adanya pelatihan yang mampu memberikan dan meningkatkan keterampilan yang dibutuhkan karyawan; c) pemberdayaan berpengaruh positif terhadap kepuasan kerja karyawan atau dengan kata lain kepuasan kerja karyawan akan meningkat karena adanya pemberdayaan terhadap karyawan dalam melaksanakan pekerjaannya; d) pemberdayaan berpengaruh positif terhadap kinerja karyawan atau dengan kata lain peningkatan kinerja karyawan dapat disebabkan karena karyawan diberdayakan dengan baik; e) kepuasan kerja karyawan berdampak positif terhadap kinerja karyawan atau dengan kata lain peningkatan kinerja karyawan dapat disebabkan karena karyawan merasa puas terhadap berbagai aspek dari pekerjaanya; f) pengaruh pelatihan terhadap kepuasan kerja karyawan akan berdampak pada kinerja karyawan atau dengan kata lain meningkatnya kepuasan kerja karyawan sebagai akibat karyawan memperoleh pelatihan yang sesuai dengan kebutuhannya akan dapat meningkatkan kinerja karyawan; g) pengaruh pemberdayaan terhadap kepuasan kerja akan berdampak pada kinerja karyawan atau dengan kata lain kepuasan kerja akan meningkat dengan adanya pemberdayaan yang baik yang selanjutnya akan meningkatkan kinerja karyawan.

Berdasarkan hasil kajian yang dilakukan dalam penelitian ini diharapkan dapat memberikan kontribusi untuk pengembangan keilmuan terutama bidang manajemen sumberdaya manusia dan perilaku organisasi. Model yang digunakan dalam penelitian ini merupakan pengembangan dari hasil penelitian sebelumnya, dimana dalam penelitian ini model merupakan integrasi pengaruh antar konstruk pelatihan, pemberdayaan, kepuasan kerja karyawan, dan kinerja karyawan yang belum dilakukan oleh peneliti sebelumnya. Untuk menguji dan menganalisis pengaruh antar konstruk dalam model digunakan pendekatan analisis struktural.

Saran diajukan untuk PT. Madubaru Yogyakarta adalah perusahaan perlu meningkatkan dalam penggunaan metode pelatihan yang lebih akurat agar tujuan pelatihan lebih mudah tercapai. Sedangkan dari sisi pemberdayaan, perusahaan perlu menekankan lebih lanjut dalam tujuan pemberdayaan yang lebih mengarah pada peningkatan kinerja karyawan, sehingga selain karyawan merasakan kepuasan karena merasa diberi kepercayaan oleh perusahaan namun di sisi lain karyawan harus mampu meningkatkan kinerja mereka dengan adanya kepercayaan yang diberikan melalui pemberdayaan tersebut. Secara umum, kepuasan kerja karyawan sudah menunjukkan kondisi yang baik, maka kondisi tersebut harus dipertahankan dan perlakuan yang selama ini dilakukan terhadap karyawan sebaiknya ditingkatkan lagi agar perasaan senang karyawan pada pekerjaanya semakin meningkat. Kinerja karyawan sudah menunjukkan kondisi yang positif, oleh karena itu perusahaan perlu mempertahankan dan meningkatkannya. Hal ini diperlukan untuk mempermudah perusahaan dalam mencapai target di masa depan, dimana berdasarkan hasil penelitian ini dapat dilakukan melalui pelatihan dan pemberdayaan serta dengan memperhatikan kepuasan kerja karyawan. Selanjutnya, untuk penelitian berikutnya dapat mengembangkan 
model dengan menambahkan organisasional komitmen dan retensi (Nkosi, 2015; Ongori, 2009) untuk obyek yang sama atau berbeda dan dengan sampel yang lebih besar ataupun menggunakan metode analisis lain, baik dengan pendekatan kuantitatif atau kualitatif.

\section{Daftar Referensi}

Adesole, M.A., Oyeniyi, K.O., \& Adeyemi, M.A. (2013). Empirical study of the relationship between staff training and job satisfaction among Nigerian Banks employees. Internasional Journal of Academic Research in Economic and Management Sciences, 2(6), 108-115.

Armstrong, M. (2006). A Handbook of Human Resource Management Practice (Tenth Edition). New York: Kogan Page.

Ataunur, I., \& Ariyanto, E. (2015). Pengaruh Kompetensi dan Pelatihan Terhadap Kinerja Karyawan PT Adaro Energy. Telaah Bisnis, 16(2), 135-149.

Ayuningtyas, H., \& Djastuti, I. (2017). Analisis Pengaruh Pemberdayaan Dan Pengembangan Karir Terhadap Kinerja Karyawan Dengan Kepuasan Kerja Sebagai Variabel Intervening (Studi Pada Karyawan PDAM Tirta Moedal Kota Semarang). Diponegoro Journal Of Management, 6(3), 1-13.

Bandura, A. (1986). Social foundations of thought and action: A social cognitive theory. Englewood Cliffs, New Jersey: Prentice Hall.

Bangun, P.W. (2012). Manajemen Sumber Daya Manusia. Jakarta: Erlangga.

Bakotic', D.F., \& Babic', T. (2013). Relationship between working condition and job satisfaction: The case of Croatian Shipbuilding Company. International Journal of Business and Social Science, 4(2), 206-213.

Buckley, R., \& Caple, J. (2009). The theory and practice of training (Sixth Edition). New York: Kogan Page.

Chang, L.C., Shih, C.H., \& Lin, S.M. (2010). The mediating role of psychological empowerment on job satisfaction and organizational commitment for school health nurses: A cross-sectional questionnaire survey. International Journal of Nursing Studies, 47(4), 427433.

Chiang, C.F., Back, K.J., \& Canter, D.D. (2005). The impact of employee training on job satisfaction and intention to stay in the hotel industry. Journal of Human Resources in Hospitality and Tourism, 4(2), 99-118.

Conger, J.A., \& Kenungo, R.N. (1988). The empowerment process: Integrating theory and practice. Academy of Management Review, 13(3),471-482.

Davies, M., Laschinger, H. K. S., \& Andrusyszyn, M. (2006). Clinical educators' empowerment, job tension, and job satisfaction: A test of Kanter's theory. Journal for Nurses in Staff Development, 22, 78-86.

Dessler, G. (2010). Manajemen Sumber Daya Manusia (Edisi Kesepuluh). Penerjemah: Tim index. Jakarta Barat: Indeks.

Gupta, C.P, (2012). Human Resource Management. New Delhi: Sultan Chand and Sons Educational.

Ghozali, I., \& Latan, H. (2015). Partial Least Squares konsep, teknik dan aplikasi menggunakan program smartPLS 3.0. (Edisi kedua). Semarang: Badan Penerbit-Undip.

Hasibuan, M. (2014). Manajemen Sumber Daya Manusia. Jakarta: Bumi Aksara.

Heslop, P., Smith, G.D., Metcalfe, C., Macleod, J., \& Hart, C. (2002). Change in job satisfaction and its association with self-reported stress, cardiovascular risk factors, and mortality. Social Science and Medicine, 54(10), 15891599.

Irmim, S. (2005). Mengelola Potensi dan Motivasi Kerja Bawahan. Jakarta: Seyma Media.

Jacquiline, F.N. (2014). Employee empowerment and job satisfaction. Researchjournali's journal of human resource, 2(2), 1-12. 
Karatepe, O.M. (2012). Perceived organizational support, career satisfaction, and performance outcomes: a study of hotel employees in Cameroon. International Journal of Contemporary Hospitality Management, 24(5), 735752.

Kartikasari, R. I., \& Djastuti, I. (2017). Pengaruh Pelatihan dan Disiplin Kerja Terhadap Kinerja Karyawan Dengan Kepuasan Kerja Sebagai Variabel Intervening (Studi Pada SPBE PT Tunas Sejati Cilacap). Diponegoro Journal Of Management, 6(4), 1-12.

Khan, A.H., Nawaz, M.M., Aleem,M., \& Hamed, W. (2011). Impact of Job satisfaction on employees performance: An empirical study of autonomous Medical Institutions of Pakistan. African Journal of Business Management, 6(7), 2697-2705.

Khuong, M.N., \& Tien, B.D. (2013). Factors influencing employee loyalty directly and indirectly through job satisfactionA study of banking sector in Ho Chi Minh City. International Journal of Current Research and Academic Review, 1(4),81-95.

Luthans, F. (2005). Organizational behavior (Tenth Edition). New York: McGrew Hill.

Madura, J. (2007). Pengantar Bisnis (Edisi 4). Jakarta: Salemba Empat.

Mangkunegara, A. P. (2009). Manajemen Sumber Daya Manusia Perusahaan. Bandung: Remaja Rosdakarya.

Mathis, R.L., \& Jackson, J.H. (2000). Human Resource management (Ninth Edition). South-West College, Ohio: Thomson Learning.

Mohammed, F., \& Eleswed, M. (2013). Job satisfaction and organizational commitment: A correlational study in Bahrain. International Journal of Business, Humanities and Technology, 3(5), 43-53.

Nielsen, J. F., \& Pedersen, C. P. (2003). The consequences and limits of empowerment in financial services.
Scandinavian Journal of Management, 19, 63-83.

Nkosi, S.M. (2015). Effects of training on employee commitment, retention and performance: A case study of a Local Municipality in South Africa. European Journal of Business and Management, 7(15), 104-108.

Notoatmodjo, S. (2009). Pengembangan Sumber Daya Manusia. Jakarta: Rineka Cipta.

Ongori, H. (2009). Managing behind the scenes: A view point on employee empowerment. African of Business Management, 3(1), 009-015.

Palo, S., \& Padhi, N.(2003). Measuring effectiveness of TQM training: an Indian study. International journal of training and development, 7(3), 203-216.

Pratama, I. B., \& Sriathi, A. A. (2015). Pengaruh Stres Kerja dan Pemberdayaan Terhadap Kepuasan Kerja Karyawan di Prama Hotel. E-Journal Manajemen UNUD, 4(11), 3565-3591.

Rae, K. (2013). How perceptions of empowerment and commitment affect job satisfaction of managerial-level effects. Accounting, Accountability and Performance, 18(1), 1-32.

Rizwan, M., Khan, W.M., Tariq, H.M.A., Ghafar, A., Anjum, M.Z., \& Bajwa, E.U. (2012). Empirical study of employee job satisfaction. IOSR Journal of Business and management, 29-35.

Saif, N.I., \& Saleh, A.S. (2013). Psychological empowerment and job satisfaction in Jordanian hospitals. International Journal of Humanities and Social Science, 3(16), 250-257.

Saifullah, N., Alam, M., Zafar, M.W., \& Humayon, A.A. (2015). Job satisfaction: A Contest between human and organizational beharvior. International Journal of Economic Reseach, 6(1), 4551.

Sari, O.R., \& Susilo, H. (2018). Pengaruh Kepuasan Kerja Terahap Kinerja Karyawan Dengan Organizational Citizenship Behaviour Sebagai Variabel 
Intervening. Jurnal Administrasi Bisnis (JAB), 64(1), 28-35.

Sihombing, M. F., Lie, D., Efendi, \& Chandra, E. (2016). Pengaruh Pelatihan dan Pengembangan Karir Terhadap Kepuasan Kerja Pegawai Pada Kantor Badan Penyelenggara Jaminan Sosial (BPJS) Kesehatan Cabang Pematangsiantar. Jurnal Makerting, 2(2), 2502-4434.

Sousa-Poza, A. (2000). Well-being at work. A cross-national analysis of the levels and determinants of job satisfaction. Journal Sociology-Economy, 29(6), 517538 .

Spector, P.E. (1997). Job Satisfaction: Aplication, Asessment, Causes, and Consequences. Thousand Oaks, California: Sage.

Spreitzer, G.M. (1995). Psychological empowerment in the workplace: Dimensions, measurement, and validation. Academy of Management Journal, 38(5), 1442-1465.

Sugiyono (2014). Metode Penelitian Bisnis. Bandung: Alfabeta.

Suryadi, E. (2010). Ananlisis Peranan Leadership dan Budaya Organisasi TerhadapKinerja Pegawai. Jurnal Manajerial, 8(16), 1-9.

Sutrisno, E. (2009). Manajemen Sumber Daya Manusia (Edisi Pertama). Jakarta:Kencana Prenada Media Group.

Thomas, K. W., \& Velthouse, B. A. (1990). Cognitive elements of empowerment:
An "interpretive" model of intrinsic task motivation. Academy of Management Review, 15, 666-681.

Utomo, H. J., \& Sugiarto, M. (2007). Manajemen Sumber Daya Manusia. Yogyakarta: Ardana Media.

Vasudevan, H. (2014). Examining the relationship of training on job satisfaction and organizational effectiveness. International Journal of Management and Business Research, 4 (3), 185-202.

Veitzal, R., \& Basri. (2005). Performance Appraisal: Sistem yang tepat untuk menilai kinerja karyawan dan meningkatkan daya saing perusahaan. Jakarta: Raja Grafindo Persada.

Wadhwa, D.S., \& Verghese, M. (2015). Impact of employee empowerment on job satisfaction and organizational commitment: An empirical investigation with special reference to selected cement industry in Chhattisgarh. International Journal in Management and Social Science, 3(3), 280-286.

Wagonhurst, C. (2002). Developing effective training programs. Journal of Research Administration, 33(2), 77.

Zhang X, \& Bartol, K.M. (2010). Linking empowering leadership and employee creativity: The influence of psychological empowerment, intrinsic motivation and creative process engagement. Academy of Management Journal, 53(1), 107-128. 